OPEN ACCESS

Edited by:

Kathleen P. Pratt,

Uniformed Services University of the Health Sciences, United States

Reviewed by: Moanaro Biswas, Indiana University, United States Trent Spencer, Emory University, United States

*Correspondence:

Qizhen Shi qshi@versiti.org

Specialty section: This article was submitted to Immunological Tolerance and Regulation,

a section of the journa Frontiers in Immunology

Received: 08 December 2019 Accepted: 24 April 2020

Published: 12 June 2020

Citation:

Cai Y and Shi Q (2020) Platelet-Targeted FVIII Gene Therapy Restores Hemostasis and Induces Immune Tolerance for Hemophilia A. Front. Immunol. 11:964 doi: 10.3389/fimmu.2020.00964

\section{Platelet-Targeted FVIII Gene Therapy Restores Hemostasis and Induces Immune Tolerance for Hemophilia A}

\author{
Yuanhua Cai ${ }^{1,2}$ and Qizhen Shi ${ }^{1,2,3,4 *}$ \\ ${ }^{1}$ Department of Pediatrics, Medical College of Wisconsin, Milwaukee, WI, United States, ${ }^{2}$ Blood Research Institute, Versiti \\ Wisconsin, Milwaukee, WI, United States, ${ }^{3}$ Children's Research Institute, Children's Wisconsin, Milwaukee, WI, \\ United States, ${ }^{4}$ MACC Fund Research Center, Milwaukee, WI, United States
}

Platelets are small anucleated blood components primarily described as playing a fundamental role in hemostasis and thrombosis. Over the last decades, increasing evidence has demonstrated the role of platelets in modulating inflammatory reactions and immune responses. Platelets harbor several specialized organelles: granules, endosomes, lysosomes, and mitochondria that can synthesize proteins with pre-stored mRNAs when needed. While the functions of platelets in the immune response are well-recognized, little is known about the potential role of platelets in immune tolerance. Recent studies demonstrate that platelet-specific FVIII gene therapy can restore hemostasis and induce immune tolerance in hemophilia A mice, even mice with preexisting anti-FVIII immunity. Here, we review the potential mechanisms by which platelet-targeted FVIII gene therapy restores hemostasis in the presence of anti-FVIII inhibitory antibodies and induces immune tolerance in hemophilia A.

Keywords: platelets, gene therapy, immune tolerance, hemophilia A, factor VIII

\section{INTRODUCTION}

Platelets are the second most common type of cells found in blood, with approximately $10^{11}$ newly produced daily to replenish the old platelets in the body $(1,2)$. Aged platelets undergo apoptosis and are phagocytosed by scavenger cells in the spleen and liver (3-5). It is increasingly recognized that platelets play fundamental roles not only in hemostasis and thrombosis but also in innate and adaptive immunity. The roles of platelets in the immune response have been extensively reviewed in many papers (6-8), but few studies indicate the role of platelets in immune tolerance. Recent studies that target platelets for gene therapy reveal the potential role of platelets in immune tolerance induction $(9,10)$.

Platelets are loaded with abundant bioactive proteins and circulate in the blood, serving as both a storage "depot" and trafficking "vehicle" in circulation. Due to these characteristics, platelets may be a unique target for gene therapy of diseases. In the past two decades, several groups have been instrumental in developing novel strategies for hemophilia A gene therapy using platelets as a target (11-20). It has been shown that ectopic expression of factor VIII (FVIII) in platelets directed by either the glycoprotein (GP) Ib or the GPIIb ( $\alpha \mathrm{IIb}$ ) promoter can lead to the storage of FVIII in platelet $\alpha$-granules and that platelet-derived FVIII can improve hemostasis in hemophilia A mice even in the presence of anti-FVIII inhibitory antibodies (referred to as inhibitors) $(13,15,17,21)$. In addition to achieving hemostatic efficacy, studies have demonstrated that lentivirus-mediated platelet-specific FVIII gene delivery under control of the $\alpha \mathrm{IIb}$ promoter (2bF8) to hematopoietic 
stem cells (HSCs) can induce antigen-specific immune tolerance in hemophilia A mice even with preexisting anti-FVIII immunity (22-24). In this review, we discuss the potential mechanisms of platelet-targeted FVIII expression in restoring hemostasis for hemophilia $\mathrm{A}$ in the presence of anti-FVIII inhibitors and inducing immune tolerization after platelet-specific gene therapy.

\section{PLATELETS SHIELD NEOPROTEIN FROM BEING RECOGNIZED BY THE IMMUNE SYSTEM}

Platelets could be an ideal target for gene therapy of hemophilia $\mathrm{A}$ as they can store neoprotein FVIII together with its carrier protein von Willebrand factor (VWF) in $\alpha$-granules and act as delivery vehicles in blood circulation. It has been shown that when FVIII expression is introduced by HSC transduction with $2 \mathrm{bF} 8$ lentivirus followed by transplantation, FVIII expression is detected only in platelets, but not in plasma of hemophilia A mice $(14,17,22,23)$. Plasma FVIII is undetectable in 2bF8-transduced recipients even with a platelet-FVIII level as high as $30-35 \mathrm{mU} / 10^{8}$ platelets (corresponding to $\sim 60-70 \%$ of FVIII in whole blood in normal wild-type C57BL/6 mice) $(22,23)$. Thus, neoprotein FVIII stored in platelets may avoid direct exposure to the immune system during the normal physiological condition, which may reduce the potential to elicit immune responses against the neoprotein. Indeed, neither inhibitory nor noninhibitory anti-FVIII antibodies were detected after plateletspecific FVIII gene therapy via $2 \mathrm{bF} 8$ lentivirus-mediated bone marrow or HSC transduction followed by transplantation. The efficacy in phenotypic correction and immune tolerance induction was further confirmed through sequential bone marrow transplantations in secondary and tertiary recipients $(14,17,22,25)$.

The effectiveness of platelet-targeted gene therapy has been further confirmed in hemophilia A rats (26) and hemophilia A dogs (27). Shi et al. recently developed a hemophilia A rat model, in which nearly the entire rat FVIII gene is inverted, with a severe spontaneous bleeding phenotype and a high incidence of inhibitor development upon rhFVIII infusion (26). Of note, the severe hemophilic phenotype in hemophilia A rats is fully rescued after platelettargeted FVIII expression. When platelet-FVIII expression was introduced into hemophilia A rats after transplantation of $2 \mathrm{bF} 8$ genetically manipulated bone marrow cells from $2 \mathrm{bF} 8$ transgenic rats, the spontaneous bleeding phenotype was rescued with no inhibitor development even though animals were continuously exposed to platelet-FVIII after bone marrow transplantation (26). Using a large animal model, hemophilia A dogs, Du and coworkers demonstrated that 2bF8 lentivirus-mediated HSC transduction followed by transplantation improved hemostasis in hemophilia A dogs and animals were well-tolerized to 2bF8 lentivirus-introduced neoprotein with no detectable inhibitor development in treated animals (27).
In contrast to platelet-specific FVIII expression, it has been shown that targeting FVIII expression to hematopoietic cells under a constitutively active promoter may trigger anti-FVIII immune responses. Wang et al. (20) utilized the intraosseous delivery of a lentiviral vector targeting FVIII to platelets (under the GPIb $\alpha$ promoter, G-F8-LV) and a lentiviral vector with constitutive FVIII expression (under the elongation factor $1 \alpha$ promoter, E-F8-LV). After a FVIII gene transfer by injecting EF8-LVs into tibias in hemophilia A mice, up to $20 \%$ of plasma FVIII activity was detected initially but dropped to undetectable levels within 2-3 months due to the development of FVIII inhibitors. In contrast, in hemophilia A mice that received GF8-LVs, platelet-derived FVIII was detected and sustained up to 160 days, and a partial phenotypic correction was achieved even with anti-FVIII inhibitors. The difference in efficacy between these two lentiviral treatments may be due to the expression pattern of FVIII. Studies from Kootstra et al. (28) also showed that hemophilia A mice developed anti-FVIII immune responses after non-specific FVIII expression in hematopoietic cells. In their study, FVIII expression was driven by the $\beta$-actin promoter (ubiquitous). They showed that all animals developed inhibitors and that transduced cells were eliminated within 4 months after gene therapy.

Besides the promoter, other factors, e.g., protein properties, may also affect the efficacy of gene therapy. Studies by Gangadharan et al. (29) demonstrated that sustained high levels of plasma FVIII were achieved in hemophilia A mice that were preconditioned with either lethal 11 Gy or sub-lethal 5.5 Gy TBI and received $\mathrm{Sca}^{+}{ }^{+}$or $\mathrm{c}-\mathrm{kit}^{+}$cells transduced with porcine FVIII driven by the mouse stem cell virus (MSCV) promoter (MSCV-porcine fVIII) using a retrovirus-mediated gene transfer system. Further studies by Ide et al. (30) demonstrated that sufficient preconditioning is critical for achieving success within MSCV-porcine fVIII/HSC gene therapy in hemophilia A mice. When hemophilia A mice were preconditioned with busulfan or busulfan plus cyclophosphamide followed by transplantation of MSCV-porcine fVIII-transduced Sca- $1^{+}$ cells, transient FVIII expression was obtained in recipients on day 7, but dropped to undetectable on day 14 and afterward due to the development of anti-FVIII inhibitors. When busulfan was supplemented with anti-thymocyte serum (ATS) for preconditioning, sustained plasma FVIII expression was achieved in mice after receiving MSCV- porcine fVIIItransduced Sca- $1^{+}$cells (30). In lentivirus-mediated platelettargeted gene therapy, busulfan alone preconditioning is sufficient for achieving sustained therapeutic levels of plateletFVIII in hemophilia A mice in the non-inhibitor model (17, 23). These studies support that targeting FVIII to platelets is unique in the hemophilia A gene therapy, because FVIII stored in platelets can be better sequestered compared to plasma FVIII as platelet-FVIII will be released together with its carrier protein VWF when it is needed, i.e., at the site of injury where platelets are activated. In addition, sheltering FVIII in platelets can protect the neoprotein from being recognized by the circulating immune cells. Sheltering FVIII in platelets protects FVIII from being inactivated by the circulating FVIII inhibitors. 


\section{THE PRESENCE OF PROTECTIVE PROTEIN VWF TO FVIII IN PLATELETS IS CRITICAL FOR OPTIMAL PLATELET GENE THERAPY OF HEMOPHILIA A}

It is well-known that VWF binds with FVIII non-covalently, which affects the expression and stability of FVIII. FVIII colocalizes with endogenous protein VWF in platelet $\alpha$-granules when FVIII is targeted to platelets $(12,13)$. Studies by Shi et al. (31) demonstrated that VWF has a protective effect on FVIII from inhibitor inactivation, and the preformed complex of VWF with FVIII has a greater protective effect on FVIII from anti-FVIII inhibitor inactivation than unbound VWF. When FVIII expression is targeted to platelets, it is stored together with endogenous VWF in a protective compartment, platelet $\alpha$-granules, where it has an opportunity to form a VWF/FVIII complex. This preformed VWF/FVIII complex will be released locally at the site of injury. Thus, it can reduce inhibitor inactivation of FVIII, achieving hemostatic efficacy.

Further studies by Shi et al. (32) using $2 \mathrm{bF} 8$ transgenic mouse models showed that the preformed VWF/FVIII complex is vital for optimal platelet gene therapy of hemophilia A with inhibitors. VWF impacts the expression of platelet-FVIII as well as the hemostasis efficacy. Without VWF, the level of platelet-FVIII significantly decreased, and while hemostatic efficacy was still maintained in hemophilia A mice in the absence of inhibitors, it was limited in the presence of anti-FVIII inhibitors. These results demonstrate that VWF is essential to platelet-targeted gene therapy in hemophilia A with inhibitors. Using 2bF8 transgenic mice in the FVIII knockout background with varying VWF expressions, Shi et al. showed that both platelet-derived VWF and plasma-derived VWF are required for optimal platelet-derived FVIII gene therapy in hemophilia A mice with inhibitors (32).

More evidence indicating the important role of VWF in platelet FVIII gene therapy derives from studies of platelettargeted FIX gene therapy in hemophilia B mice $(33,34)$. When FIX expression is targeted to platelets under control of the same platelet-specific $\alpha \mathrm{IIb}$ promoter used in the FVIII studies, greater than $90 \%$ of FIX is stored in platelets and is releasable upon platelet activation. While the bleeding phenotype is rescued in hemophilia B mice without anti-FIX inhibitors after platelettargeted FIX gene therapy, the efficacy is nullified in the presence of the anti-FIX inhibitors (33). This differs from platelet-targeted FVIII gene therapy in hemophilia A mice, in which the treatment is effective even in the presence of anti-FVIII inhibitors. We reason that the ineffectiveness of platelet-FIX in the inhibitor model is because there is no protective protein for FIX, so functional FIX activity is rapidly neutralized by circulating antiFIX inhibitors, once released from activated transduced platelets at the site of injury.

The protective role of VWF in platelet-targeted FVIII gene therapy is not only revealed in its hemostatic function but also in immune responses. To initiate an anti-FVIII immune response, FVIII needs to be internalized by antigen-presenting cells and presented to FVIII-specific CD4 T cells. Studies done by Dasgupta et al. (35) showed that VWF protects FVIII from endocytosis by dendritic cells, which may reduce the immune response to FVIII. VWF can also modulate the repertoire of FVIII-derived peptides on antigen-presenting cells, which may affect the $\mathrm{CD} 4^{+} \mathrm{T}$ cell-mediated anti-FVIII immune response (36). Chen et al. reported that VWF could attenuate FVIII-primed CD4 $\mathrm{T}$ cell proliferation in response to rhFVIII restimulation. Their studies showed that VWF could mitigate FVIII-specific memory B cell maturation and anti-FVIII antibody production both ex vivo in a memory B cell-based ELISPOT assay and in vivo in an immunocompromised FVIII deficient animal model upon rhFVIII restimulation (37). Results from this study support the notion that FVIII stored together with VWF in platelets may be less immunogenic compared to plasma FVIII in a milieu of preexisting anti-FVIII immunity. Indeed, studies by Chen et al. demonstrated that infusion of platelets containing FVIII into hemophilia A mice with pre-existing antiFVIII immunity did not trigger a memory immune response, but robust memory immune responses were elicited when a similar amount of rhFVIII was infused into plasma (38).

Thus, in our platelet-targeted gene therapy protocol, the association of VWF and FVIII is pivotal for clinical efficacy in hemophilia A with inhibitors. The VWF/FVIII complex protects FVIII from being inactivated by the inhibitors after a burst of VWF/FVIII complex released at the site of injury.

\section{PROPER PRECONDITIONING BEFORE GENE TRANSFER IS IMPORTANT FOR ACHIEVING SUSTAINED PLATELET-FVIII EXPRESSION AND IMMUNE TOLERANCE INDUCTION IN PLATELET GENE THERAPY}

Proper preconditioning is essential for immune tolerance induction in our platelet-targeted FVIII gene therapy protocol. Chen et al. (38) reported that the infusion of platelets containing FVIII to hemophilia A mice neither triggered immune responses nor induced immune tolerance to FVIII. However, immune tolerance was induced in mice preconditioned with $6.6 \mathrm{~Gy}$ followed by $2 \mathrm{bF} 8$ transgenic platelet infusion (38). This could be because the proper preconditioning followed by the introduction of platelet-derived FVIII helps to reconstruct the immune system, especially in the early phases $(<8$ weeks) of bone marrow reconstitution. It has been shown that ultraviolet (UV) irradiation before antigen immunization could promote antigen-specific immune tolerance through Treg cell induction in mice (39). Studies by Zheng et al. revealed that $\mathrm{T}$ cell reconstitution favored Treg differentiation when the mice received sub-lethal irradiation (40). Also, preconditioning can induce large amounts of apoptotic cells, which has been shown to create an immunosuppressive microenvironment (41). All these studies indicate the importance of preconditioning in inducing immune tolerance.

The optimal preconditioning regimen for platelet-FVIII gene therapy to establish immune tolerance while achieving sustained platelet-FVIII expression is more stringent than that used to achieve sustained platelet-FVIII expression alone 
in unprimed hemophilia A mice. Chen et al. (23) showed that sustained platelet-FVIII expression was achieved, and no anti-FVIII antibodies were detected in 2bF8 lentivirustransduced recipients preconditioned with either myeloablative 11 Gy TBI, non-myeloablative 6.6 Gy TBI, busulfan, or busulfan plus ATG. Further studies showed that even after rhFVIII immunization, none of the recipients developed inhibitors in the groups preconditioned with an optimized preconditioning regimen, $6.6 \mathrm{~Gy}$ TBI or busulfan plus ATG. In contrast, 25 and $40 \%$ of the recipients developed inhibitors in the $11 \mathrm{~Gy}$ TBI group and the busulfan group, respectively, when they were challenged with the same rhFVIII immunization protocol (23). It's still unclear how preconditioning impacts immune tolerance induction, but studies from our laboratory demonstrate that proper preconditioning is important in our platelet-targeted gene therapy protocol. We speculate that a lethal dose of irradiation (11 Gy TBI) may severely disrupt the intestinal immune system (42), which may impact Treg cell homeostasis in the body. The 11 Gy TBI myeloablative preconditioning may disrupt Treg differentiation, dampening the efficacy of immune tolerance induction after platelet-targeted gene therapy. Thus, proper preconditioning is critical for the effectiveness of platelet-targeted gene therapy in restoring hemostasis and inducing immune tolerance in hemophilia A.

\section{PERIPHERAL TOLERANCE IS ESTABLISHED AFTER PLATELET-TARGETED 2bF8 GENE THERAPY}

Multiple lines of evidence suggest that both primary and secondary anti-FVIII immune responses are CD4T celldependent (43-52). Studies from Chen et al. (23) demonstrated that the immune tolerance induced by $2 \mathrm{bF} 8$ lentivirusmediated gene therapy is CD4 T cell-mediated. Chen et al. found that Treg cells increased in 2bF8-transduced recipients. Using a $\mathrm{T}$ cell proliferation assay, they showed that $\mathrm{CD} 4^{+}$ $\mathrm{T}$ cells from rhFVIII-immunized $2 \mathrm{bF} 8$ lentivirus-transduced recipients' spleens did not respond to rhFVIII restimulation when co-cultured with dendritic cells from deficient (FVIII ${ }^{\text {null }}$ ) mice. Further studies using a FVIII-specific memory B cell differentiation assay showed that CD4T cells from FVIIIimmunized 2bF8 lentivirus-transduced recipients could not promote memory $\mathrm{B}$ cell maturation into antibody-secreting cells, but memory B cells from FVIII-immunized 2bF8transduced recipients could differentiate into antibody-secreting cells when co-cultured with CD4 $\mathrm{T}$ cells isolated from FVIIIprimed untransduced FVIII ${ }^{\text {null }}$ mice. Further studies showed that immune tolerance is transferable when splenocytes from $2 \mathrm{bF} 8$ transduced recipients were infused into naive FVIII ${ }^{\text {null }}$ mice (23). Together, data from these studies demonstrate that immune tolerance established in 2bF8 lentivirus-transduced recipients is mediated by the CD4 T cell compartment.
To further investigate how immune tolerance is established after platelet-targeted gene transfer, Luo et al. (10) used the OVA model and utilized the OVA-specific T cell receptor transgenic mice to elucidate the potential mechanisms. They found that antigen-specific CD4 T cells were deleted in peripheral lymphoid organs (spleen and lymph nodes), but not in the thymus, and antigen-specific Treg cells were expanded after platelet-targeted OVA gene transfer. The specific mechanisms related to the OVA expression levels. The deletion of peripheral antigen-specific CD4 T cells was more prominent in mice with a higher level of OVA expression, whereas with a lower OVA level, the increase in antigen-specific Treg cells was dominant. Importantly, even with a lower expression level of ectopic protein, platelet-specific OVA gene transfer could still induce immune tolerance in the unprimed model. The OVA model study reveals that there are dual underlying mechanisms that are responsible for establishing antigen-specific immune tolerance after platelet-targeted gene therapy.

\section{CONCLUSION}

Platelets play fundamental roles not only in hemostasis and thrombosis but also in innate and adaptive immunity. Data from preclinical trials using animal models have demonstrated that platelet-targeted FVIII gene therapy is effective in treating hemophilia A mice even with inhibitors. Platelet-targeted gene therapy can promote antigen-specific immune tolerance through peripheral tolerance mechanisms. The effectiveness of platelet gene therapy in hemophilia A with inhibitors could be attributed to many pivotal factors, including the shielding of neoprotein by platelets from being recognized by the immune system, the presence of a protective protein VWF in the platelets, and proper preconditioning before gene transfer. In conclusion, platelettargeted gene therapy is a unique approach for gene therapy of hemophilia A even with inhibitors as it can provide not only therapeutic protein but also induce antigen-specific immune tolerance.

\section{AUTHOR CONTRIBUTIONS}

YC contributed to manuscript writing. QS conceived the structure of the review and wrote the manuscript.

\section{FUNDING}

This work was supported by National Institutes of Health, National Heart, Lung, and Blood Institute grant HL-102035 (QS), National Hemophilia Foundation Bridge Award (QS), Children's Research Institute Pilot Grant (QS), and generous gifts from the Children's Wisconsin Foundation (QS) and Midwest Athletes Against Childhood Cancer Fund (QS). 


\section{REFERENCES}

1. Branehog I, Ridell B, Swolin B, Weinfeld A. Megakaryocyte quantifications in relation to thrombokinetics in primary thrombocythaemia and allied diseases. Scand J Haematol. (1975) 15:321-32. doi: 10.1111/j.1600-0609.1975.tb01087.x

2. Kaushansky K. The molecular mechanisms that control thrombopoiesis. JClin Invest. (2005) 115:3339-47. doi: 10.1172/JCI26674

3. Nayak MK, Kulkarni PP, Dash D. Regulatory role of proteasome in determination of platelet life span. J Biol Chem. (2013) 288:682634. doi: $10.1074 /$ jbc.M112.403154

4. Alonzo MT, Lacuesta TL, Dimaano EM, Kurosu T, Suarez LA, Mapua CA, et al. Platelet apoptosis and apoptotic platelet clearance by macrophages in secondary dengue virus infections. I Infect Dis. (2012) 205:13219. doi: $10.1093 /$ infdis/jis 180

5. Wang Y, Hayes V, Jarocha D, Sim X, Harper DC, Fuentes R, et al. Comparative analysis of human ex vivo-generated platelets vs megakaryocytegenerated platelets in mice: a cautionary tale. Blood. (2015) 125:362736. doi: 10.1182/blood-2014-08-593053

6. Iannacone M. Platelet-mediated modulation of adaptive immunity. Semin Immunol. (2016) 28:555-60. doi: 10.1016/j.smim.2016.10.008

7. Semple JW, Italiano JE Jr, Freedman J. Platelets and the immune continuum. Nat Rev Immunol. (2011) 11:264-74. doi: 10.1038/nri2956

8. Xu XR, Zhang D, Oswald BE, Carrim N, Wang X, Hou Y, et al. Platelets are versatile cells: new discoveries in hemostasis, thrombosis, immune responses, tumor metastasis and beyond. Crit Rev Clin Lab Sci. (2016) 53:40930. doi: 10.1080/10408363.2016.1200008

9. Shi Q. Platelet-targeted gene therapy for hemophilia. Mol Ther Methods Clin Dev. (2018) 9:100-8. doi: 10.1016/j.omtm.2018.01.011

10. Luo X, Chen J, Schroeder JA, Allen KP, Baumgartner CK, Malarkannan S, et al. Platelet gene therapy promotes targeted peripheral tolerance by clonal deletion and induction of antigen-specific regulatory T cells. Front Immunol. (2018) 9:1950. doi: 10.3389/fimmu.2018.01950

11. Shi Q, Wilcox DA, Fahs SA, Kroner PA, Montgomery RR. Expression of human factor VIII under control of the platelet-specific alphaIIb promoter in megakaryocytic cell line as well as storage together with VWF. Mol Genet Metab. (2003) 79:25-33. doi: 10.1016/S1096-7192(03)00049-0

12. Yarovoi HV, Kufrin D, Eslin DE, Thornton MA, Haberichter SL, Shi Q, et al. Factor VIII ectopically expressed in platelets: efficacy in hemophilia a treatment. Blood. (2003) 102:4006-13. doi: 10.1182/blood-2003-05-1519

13. Shi Q, Wilcox DA, Fahs SA, Weiler H, Wells CW, Cooley BC, et al. Factor VIII ectopically targeted to platelets is therapeutic in hemophilia a with high-titer inhibitory antibodies. J Clin Invest. (2006) 116:197482. doi: $10.1172 /$ JCI28416

14. Shi Q, Wilcox DA, Fahs SA, Fang J, Johnson BD, Du LM, et al. Lentivirusmediated platelet-derived factor VIII gene therapy in murine haemophilia A. J Thromb Haemost. (2007) 5:352-61. doi: 10.1111/j.1538-7836.2007.02346.x

15. Shi Q, Fahs SA, Wilcox DA, Kuether EL, Morateck PA, Mareno N, et al. Syngeneic transplantation of hematopoietic stem cells that are genetically modified to express factor VIII in platelets restores hemostasis to hemophilia a mice with preexisting FVIII immunity. Blood. (2008) 112:271321. doi: 10.1182/blood-2008-02-138214

16. Greene TK, Wang C, Hirsch JD, Zhai L, Gewirtz J, Thornton MA, et al. In vivo efficacy of platelet-delivered, high specific activity factor VIII variants. Blood. (2010) 116:6114-22. doi: 10.1182/blood-2010-06-293308

17. Kuether EL, Schroeder JA, Fahs SA, Cooley BC, Chen Y, Montgomery RR, et al. Lentivirus-mediated platelet gene therapy of murine hemophilia a with pre-existing anti-factor VIII immunity. J Thromb Haemost. (2012) 10:157080. doi: 10.1111/j.1538-7836.2012.04791.x

18. Miao CH. Hemophilia a gene therapy via intraosseous delivery of factor VIIIlentiviral vectors. Thromb J. (2016) 14:41. doi: 10.1186/s12959-016-0105-1

19. Damon AL, Scudder LE, Gnatenko DV, Sitaraman V, Hearing P, Jesty J, et al. Altered bioavailability of platelet-derived factor VIII during thrombocytosis reverses phenotypic efficacy in haemophilic mice. Thromb Haemost. (2008) 100:1111-22. doi: 10.1160/TH08-04-0242

20. Wang X, Shin SC, Chiang AF, Khan I, Pan D, Rawlings DJ, et al. Intraosseous delivery of lentiviral vectors targeting factor VIII expression in platelets corrects murine hemophilia A. Mol Ther. (2015) 23:61726. doi: $10.1038 / \mathrm{mt} .2015 .20$
21. Gewirtz J, Thornton MA, Rauova L, Poncz M. Platelet-delivered factor VIII provides limited resistance to anti-factor VIII inhibitors. J Thromb Haemost. (2008) 6:1160-6. doi: 10.1111/j.1538-7836.2008.02992.x

22. Schroeder JA, Chen Y, Fang J, Wilcox DA, Shi Q. In vivo enrichment of genetically manipulated platelets corrects the murine hemophilic phenotype and induces immune tolerance even using a low multiplicity of infection. $J$ Thromb Haemost. (2014) 12:1283-93. doi: 10.1111/jth.12633

23. Chen Y, Luo X, Schroeder JA, Chen J, Baumgartner CK, Hu J, et al. Immune tolerance induced by platelet-targeted factor VIII gene therapy in hemophilia a mice is CD4 T cell mediated. J Thromb Haemost. (2017) 15:1994-2004. doi: 10.1111/jth.13800

24. Chen J, Schroeder JA, Luo X, Montgomery RR, Shi Q. The impact of GPIbalpha on platelet-targeted FVIII gene therapy in hemophilia a mice with pre-existing anti-FVIII immunity. J Thromb Haemost. (2019) 17:44959. doi: $10.1111 /$ jth. 14379

25. Gao C, Schroeder JA, Xue F, Jing W, Cai Y, Scheck A, et al. Nongenotoxic antibody-drug conjugate conditioning enables safe and effective platelet gene therapy of hemophilia a mice. Blood Adv. (2019) 3:2700-11. doi: 10.1182/bloodadvances.2019000516

26. Shi Q, Mattson JG, Fahs SA, Geurts AM, Weiler H, Montgomery RR. The severe spontaneous bleeding phenotype in a novel hemophilia a rat model is rescued by platelet FVIII expression. Blood Adv. (2020) 4:5565. doi: 10.1182/bloodadvances.2019000944

27. DU LM, Nurden P, Nurden AT, Nichols TC, Bellinger DA, Jensen ES, Haberichter SL, et al. Platelet-targeted gene therapy with human factor VIII establishes haemostasis in dogs with haemophilia A. Nat Commun. (2013) 4:2773. doi: $10.1038 /$ ncomms 3773

28. Kootstra NA, Matsumura R, Verma IM. Efficient production of human FVIII in hemophilic mice using lentiviral vectors. Mol Ther. (2003) 7:62331. doi: 10.1016/S1525-0016(03)00073-X

29. Gangadharan B, Parker ET, Ide LM, Spencer HT, Doering CB. High-level expression of porcine factor VIII from genetically modified bone marrow-derived stem cells. Blood. (2006) 107:385964. doi: 10.1182/blood-2005-12-4961

30. Ide LM, Gangadharan B, Chiang KY, Doering CB, Spencer HT. Hematopoietic stem-cell gene therapy of hemophilia a incorporating a porcine factor VIII transgene and nonmyeloablative conditioning regimens. Blood. (2007) 110:2855-63. doi: 10.1182/blood-2007-04-082602

31. Shi Q, Kuether EL, Schroeder JA, Perry CL, Fahs SA, Cox GJ, et al. Factor VIII inhibitors: Von Willebrand factor makes a difference in vitro and in vivo. $J$ Thromb Haemost. (2012) 10:2328-37. doi: 10.1111/j.1538-7836.2012.04902.x

32. Shi Q, Schroeder JA, Kuether EL, Montgomery RR. The important role of von willebrand factor in platelet-derived FVIII gene therapy for murine hemophilia a in the presence of inhibitory antibodies. J Thromb Haemost. (2015) 13:1301-9. doi: 10.1111/jth.13001

33. Zhang G, Shi Q, Fahs SA, Kuether EL, Walsh CE, Montgomery RR. Factor IX ectopically expressed in platelets can be stored in alpha-granules and corrects the phenotype of hemophilia B mice. Blood. (2010) 116:123543. doi: 10.1182/blood-2009-11-255612

34. Chen Y, Schroeder JA, Kuether EL, Zhang G, Shi Q. Platelet gene therapy by lentiviral gene delivery to hematopoietic stem cells restores hemostasis and induces humoral immune tolerance in FIX(null) mice. Mol Ther. (2014) 22:169-77. doi: 10.1038/mt.2013.197

35. Dasgupta S, Repesse Y, Bayry J, Navarrete AM, Wootla B, Delignat $\mathrm{S}$, et al. VWF protects FVIII from endocytosis by dendritic cells and subsequent presentation to immune effectors. Blood. (2007) 109:61012. doi: 10.1182/blood-2006-05-022756

36. Sorvillo N, Hartholt RB, Bloem E, Sedek M, ten BA, van der Zwaan $\mathrm{C}$, et al. Von Willebrand factor binds to the surface of dendritic cells and modulates peptide presentation of factor VIII. Haematologica. (2016) 101:309-18. doi: 10.3324/haematol.2015.137067

37. Chen J, Schroeder JA, Luo X, Shi Q. The impact of Von Willebrand factor on factor VIII memory immune responses. Blood Adv. (2017) 1:156574. doi: 10.1182/bloodadvances.2017009209

38. Chen Y, Schroeder JA, Chen J, Luo X, Baumgartner CK, Montgomery RR, et al. The immunogenicity of platelet-derived FVIII in hemophilia a mice with or without preexisting anti-FVIII immunity. Blood. (2016) 127:134654. doi: 10.1182/blood-2015-08-662916 
39. Hori T, Kuribayashi K, Saito K, Wang L, Torii M, Uemoto S, et al. Ultravioletinduced alloantigen-specific immunosuppression in transplant immunity. World J Transplant. (2015) 5:11-8. doi: 10.5500/wjt.v5.i1.11

40. Zheng X, Guo Y, Wang L, Zhang H, Wang S, Wang L, et al. Recovery profiles of T-cell subsets following low-dose total body irradiation and improvement with cinnamon. Int J Radiat Oncol Biol Phys. (2015) 93:111826. doi: 10.1016/j.ijrobp.2015.08.034

41. Voll RE, Herrmann M, Roth EA, Stach C, Kalden JR, Girkontaite I. Immunosuppressive effects of apoptotic cells. Nature. (1997) 390:3501. doi: $10.1038 / 37022$

42. Garg S, Boerma M, Wang J, Fu Q, Loose DS, Kumar KS, et al. Influence of sublethal total-body irradiation on immune cell populations in the intestinal mucosa. Radiat Res. (2010) 173:469-78. doi: 10.1667/RR1742.1

43. Jacquemin M, Vantomme V, Buhot C, Lavend'homme R, Burny W, Demotte $\mathrm{N}$, et al. CD4+ T-cell clones specific for wild-type factor VIII: a molecular mechanism responsible for a higher incidence of inhibitor formation in mild/moderate hemophilia A. Blood. (2003) 101:13518. doi: 10.1182/blood-2002-05-1369

44. Reding MT, Wu H, Krampf M, Okita DK, Diethelm-Okita BM, Key NS, et al. CD4+ $\mathrm{T}$ cell response to factor VIII in hemophilia A, acquired hemophilia, and healthy subjects. Thromb Haemost. (1999) 82:50915. doi: 10.1055/s-0037-1615873

45. Reding MT, Wu H, Krampf M, Okita DK, Diethelm-Okita BM, Key NS, et al. CD4+ T cells specific for factor VIII as a target for specific suppression of inhibitor production. Adv Exp Med Biol. (2001) 489:11934. doi: 10.1007/978-1-4615-1277-6_11

46. Reding MT, Lei S, Lei H, Green D, Gill J, Conti-Fine BM. Distribution of Th1- and Th2-induced anti-factor VIII IgG subclasses in congenital and acquired hemophilia patients. Thromb Haemost. (2002) 88:56875. doi: 10.1055/s-0037-1613257

47. Reding MT, Okita DK, Diethelm-Okita BM, Anderson TA, ContiFine BM. Epitope repertoire of human $\mathrm{CD} 4(+) \mathrm{T}$ cells on the A3 domain of coagulation factor VIII. J Thromb Haemost. (2004) 2:138594. doi: 10.1111/j.1538-7836.2004.00850.x
48. Reding MT, Okita DK, Diethelm-Okita BM, Anderson TA, ContiFine BM. Human CD4+ T-cell epitope repertoire on the C2 domain of coagulation factor VIII. J Thromb Haemost. (2003) 1:1777-84. doi: 10.1046/j.1538-7836.2003.00251.x

49. Reding MT, Wu H, Krampf M, Okita DK, Diethelm-Okita BM, Christie $\mathrm{BA}$, et al. Sensitization of CD4+ $\mathrm{T}$ cells to coagulation factor VIII: response in congenital and acquired hemophilia patients and in healthy subjects. Thromb Haemost. (2000) 84:643-52. doi: 10.1055/s-0037-16 14081

50. Hausl C, Ahmad RU, Schwarz HP, Muchitsch EM, Turecek PL, Dorner $\mathrm{F}$, et al. Preventing restimulation of memory B cells in hemophilia A: a potential new strategy for the treatment of antibody-dependent immune disorders. Blood. (2004) 104:115-22. doi: 10.1182/blood-200307-2456

51. Steinitz KN, van Helden PM, Binder B, Wraith DC, Unterthurner S, Hermann C, et al. CD4+ T-cell epitopes associated with antibody responses after intravenously and subcutaneously applied human FVIII in humanized hemophilic E17 HLA-DRB1*1501 mice. Blood. (2012) 119:407382. doi: 10.1182/blood-2011-08-374645

52. Jing W, Chen J, Cai Y, Chen Y, Schroeder JA, Johnson BD, et al. Induction of activated $\mathrm{T}$ follicular helper cells is critical for anti-FVIII inhibitor development in hemophilia A mice. Blood Adv. (2019) 3:3099110. doi: 10.1182/bloodadvances. 2019000650

Conflict of Interest: The authors declare that the research was conducted in the absence of any commercial or financial relationships that could be construed as a potential conflict of interest.

Copyright (c) 2020 Cai and Shi. This is an open-access article distributed under the terms of the Creative Commons Attribution License (CC BY). The use, distribution or reproduction in other forums is permitted, provided the original author(s) and the copyright owner(s) are credited and that the original publication in this journal is cited, in accordance with accepted academic practice. No use, distribution or reproduction is permitted which does not comply with these terms. 